\title{
Pyro-synthesis of $\mathrm{Na}_{2} \mathrm{FeP}_{2} \mathrm{O}_{7}$ Nano-plates as Cathode for Sodium-ion Batteries with Long Cycle Stability
}

\author{
Jinju Song, Juhyun Yang, Muhammad Hilmy Alfaruqi, Wangeun Park, Sohyun Park, Sungjin Kim, \\ Jeonggeun Jo, and Jaekook Kim ${ }^{\dagger}$
}

Department of Materials Science and Engineering, Chonnam National University, Gwangju 61186, Korea

(Received July 1, 2016; Revised July 16, 2016; Accepted July 18, 2016)

\begin{abstract}
Carbon-coated sodium iron pyrophosphate $\left(\mathrm{Na}_{2} \mathrm{FeP}_{2} \mathrm{O}_{7}\right)$ was prepared by a simple and low-cost pyro-synthesis route for further use as the cathode for Na-ion batteries. The X-ray diffraction (XRD) pattern of the sample annealed at $650^{\circ} \mathrm{C}$ confirmed the pure triclinic phase of $\mathrm{Na}_{2} \mathrm{FeP}_{2} \mathrm{O}_{7}$. Electron microscopy studies revealed a cross linked plate shape morphology of the $\mathrm{Na}_{2} \mathrm{FeP}_{2} \mathrm{O}_{7}$ sample. When tested for application in Na-ion battery, the $\mathrm{Na}_{2} \mathrm{FeP}_{2} \mathrm{O}_{7}$ cathode showed two redox pairs in the potential window of 2.0-4.0 V. The cathode registered initial discharge and charge capacities of 80.85 and $90 \mathrm{mAh} / \mathrm{g}$, respectively, with good cycling performance.
\end{abstract}

Key words : Pyro-synthesis, Sodium iron pyrophosphate, Sodium ion batteries

\section{Introduction}

$\mathrm{L}$ i-ion batteries are mainly used to power portable electronics including cell phones, laptop computers, and electric vehicles. However, the Li-ion battery technology has several limitations including safety issues, cycle life, and high cost. Furthermore, lithium ion batteries are now being utilized on a large scale. In this light, Na-ion batteries have become an important alternative because of their high energy density, easy availability, and the environmental benignity of sodium. ${ }^{1-4)}$

However, it is necessary to develop high-performance sodium battery cathodes by identifying new intercalation hosts and/or performing structural modifications of existing materials using various synthetic strategies. The choice of phosphate-based Na-insertion hosts is due to the strong covalent $\left(\mathrm{PO}_{4}\right)^{3-}$ units that provide structural stability even at high charge states and address thermal safety concerns, in contrast with commercial Li-insertion oxide hosts such as $\mathrm{LiCoO}_{2}{ }^{5}{ }^{5}$ Oxide materials may undergo oxygen evolution at high states of charge and elevated temperatures, potentially leading to explosions." ${ }^{6}$ Phosphate based materials, such as $\mathrm{NaVPO}_{4} \mathrm{~F}^{7}{ }^{7} \mathrm{NaMPO}_{4}{ }^{8,9)} \mathrm{Na}_{1.5} \mathrm{VOPO}_{4} \mathrm{~F}_{0.5}{ }^{10)}$ and $\mathrm{Na}_{2} \mathrm{FePO}_{4} \mathrm{~F},{ }^{11,12)}$ have been studied as active materials. Among them, only a few iron-based polyanionic compounds have been characterized and tested for sodium ion batteries. $\mathrm{Na}_{2} \mathrm{FeP}_{2} \mathrm{O}_{7}$ shows a theoretical capacity of $97 \mathrm{mAh} / \mathrm{g}$ with promising electrochemical properties involving $\mathrm{Fe}^{3+} / \mathrm{Fe}^{2+}$ redox activity at 3.0 V. Moreover, its 3D framework provides facile ionic con-

${ }^{\dagger}$ Corresponding author : Jaekook Kim

E-mail : jaekook@chonnam.ac.kr

Tel : +82-62-530-1703 Fax : +82-62-530-1699 duction through its open channels, which are able to accommodate several sodium sites. $^{13,14)}$ Most of the studies reported on $\mathrm{P}_{2} \mathrm{O}_{7}$-based materials synthesized by conventional high temperature solid-state reactions. ${ }^{7,15)}$ However, conventional solid-state reactions require high sintering temperature and long sintering time inducing unwanted particle growth which leads to poor electrochemical properties. A cost-effective and simple strategy to synthesize $\mathrm{Na}_{2} \mathrm{FeP}_{2} \mathrm{O}_{7}$ is hence highly desired.

In this work, we synthesized triclinic $\mathrm{Na}_{2} \mathrm{FeP}_{2} \mathrm{O}_{7}$ powders with high crystallinity by a one-step pyro-synthetic strategy using a polyol medium at a low temperature within a few minutes of reaction time in open-air condition. The polyol medium acts as a primary fuel to induce flame that can provide high thermal energy and carbon source. ${ }^{16)}$ We demonstrated that by using polyol-assisted pyro-synthesis, a pure phase $\mathrm{Na}_{2} \mathrm{FeP}_{2} \mathrm{O}_{7}$ sample can be successfully obtained. More importantly, the sample showed good cycling stability when tested for a Na-ion battery.

\section{Experimental Procedure}

$\mathrm{Na}_{2} \mathrm{FeP}_{2} \mathrm{O}_{7}$ powders were prepared by a polyol-assisted pyro-synthetic method using sodium acetate $\left(\mathrm{CH}_{3} \mathrm{COONa}, 99.0 \%\right.$. Sigma Aldrich), iron acetate $\left(\mathrm{Fe}\left(\mathrm{CO}_{2} \mathrm{CH}_{3}\right)_{2}, 99.99 \%\right.$, Sigma Aldrich), and phosphoric acid $\left(\mathrm{H}_{3} \mathrm{PO}_{4}, \geq 85 \%\right.$, Daejung). The precursors were dissolved in a beaker containing $80 \mathrm{~mL}$ of tetraethylene glycol (99.5\%, Daejung) and the solution was mixed. After stirring for $5 \mathrm{~h}$, phosphoric acid was poured and the solution was stirred for $24 \mathrm{~h}$ at room temperature. The overall molar ratio was $2: 1: 2(\mathrm{Na}: \mathrm{Fe}: \mathrm{P})$. After subsequently obtaining a homogenous solution, $50 \mathrm{~mL}$ of inflammable liquid thinner was added to the solution, which was then stirred for an hour. The final solution was uniformly poured onto a hot-plate maintained at $470^{\circ} \mathrm{C}$. The solution was ignited using a torch to induce 
incomplete combustion and the flames continued for a few minutes. After being self-extinguished, $\mathrm{Na}_{2} \mathrm{FeP}_{2} \mathrm{O}_{7}$ powders were obtained. Finally, the powders were heat-treated at $650^{\circ} \mathrm{C}$ for $6 \mathrm{~h}$ in $\mathrm{Ar}$ to remove the remaining organic compounds.

Powder X-ray diffraction (XRD) data of the samples were recorded using a Shimadzu $\mathrm{X}$-ray diffractometer with $\mathrm{Ni}$-filtered $\mathrm{Cu} \mathrm{K} \alpha$ radiation $(\lambda=1.5406 \AA)$ operated at $40 \mathrm{kV}$ and $30 \mathrm{~mA}$ within a scanning range angle from $10^{\circ}$ to $80^{\circ}(2 \theta)$. The particle morphologies and sizes were determined by FE-SEM images that were obtained using a Hitachi S-4700. The electrochemical properties of the $\mathrm{Na}_{2} \mathrm{FeP}_{2} \mathrm{O}_{7}$ samples were evaluated with sodium metal as the reference electrode using a Nagano 2004H battery tester system (Nagano Keiki Co., Ltd., Ohtaku, Tokyo, Japan). The fabricated cathode consisted of active materials with $30 \%$ conductive carbon (Ketjen black) and teflonized acethylene black (TAB). The mixture was pressed onto a stainless steel mesh and dried under a vacuum at $120^{\circ} \mathrm{C}$ for $12 \mathrm{~h}$. A 2032 coin type cell consisting of the cathode and a sodium metal anode separated by glass fiber was fabricated in an Ar-filled glove box and aged for $12 \mathrm{~h}$ before the electrochemical measurements. The electrolyte employed was $1 \mathrm{M} \mathrm{NaClO}_{4}$ in propylene carbonate (PC). The assembled cells were tested at $0.08 \mathrm{C}$ in a voltage range from 2.0 to $4.0 \mathrm{~V}$.

\section{Results and Discussion}

The XRD patterns of the as-prepared and annealed $\mathrm{Na}_{2} \mathrm{FeP}_{2} \mathrm{O}_{7}$ samples are shown in Fig. 1. The diffraction peaks of the as-prepared sample were broad, indicating an amorphous nature. In contrast, the diffraction patterns of the sample heated in an argon atmosphere was well indexed to the triclinic phase of $\mathrm{Na}_{2} \mathrm{FeP}_{2} \mathrm{O}_{7}$ without any impurities. ${ }^{17)}$ However, according to the element analysis results, the amount of carbon from combustion synthesis of the heated $\mathrm{Na}_{2} \mathrm{FeP}_{2} \mathrm{O}_{7}$ is around $1.42 \%$. No carbon phase is detected from the XRD, indicating that the residual carbon in $\mathrm{Na}_{2} \mathrm{FeP}_{2} \mathrm{O}_{7}$ is in an amorphous state. ${ }^{18-20)}$ Therefore, the weight of the active materials in the samples was corrected during galvanostatic measurement. Interestingly, the three dimensional $\mathrm{Na}_{2} \mathrm{FeP}_{2} \mathrm{O}_{7}$ crystal structure provides large channels for facile $\mathrm{Na}^{+}$ion diffusion. This three dimensional structure is formed by corner sharing $\mathrm{FeO}_{6}$ octahedra creating $\mathrm{Fe}_{2} \mathrm{O}_{11}$ dimers, and these dimers are further interconnected by both corner-sharing and edge-sharing with $\mathrm{P}_{2} \mathrm{O}_{7}$ pyrophosphate groups. ${ }^{21)}$

The morphology and the particle size of the samples were examined by FE-SEM, as shown in Fig. 2. The image of $\mathrm{Na}_{2} \mathrm{FeP}_{2} \mathrm{O}_{7}$ sample showed cross linked nano-plates where the average particle size was found to be around 2-5 $\mu \mathrm{m}$ and the particles were agglomerated. Nano-plate particles may facilitate passage of the electrolyte through each nanoplate, and thus more surface sites would be accessible for sodium ions to react with the $\mathrm{Na}_{2} \mathrm{FeP}_{2} \mathrm{O}_{7}$ sample. In addition, the cross linked structures enhance the electrode-electrolyte contact area and reduce the diffusion distance of the $\mathrm{Na}^{+}$ ions, and these factors play a key role in stable cyclability. ${ }^{22)}$ It is also worth noting that high energy and short reaction time facilitate rapid nucleation and prohibit grain growth,

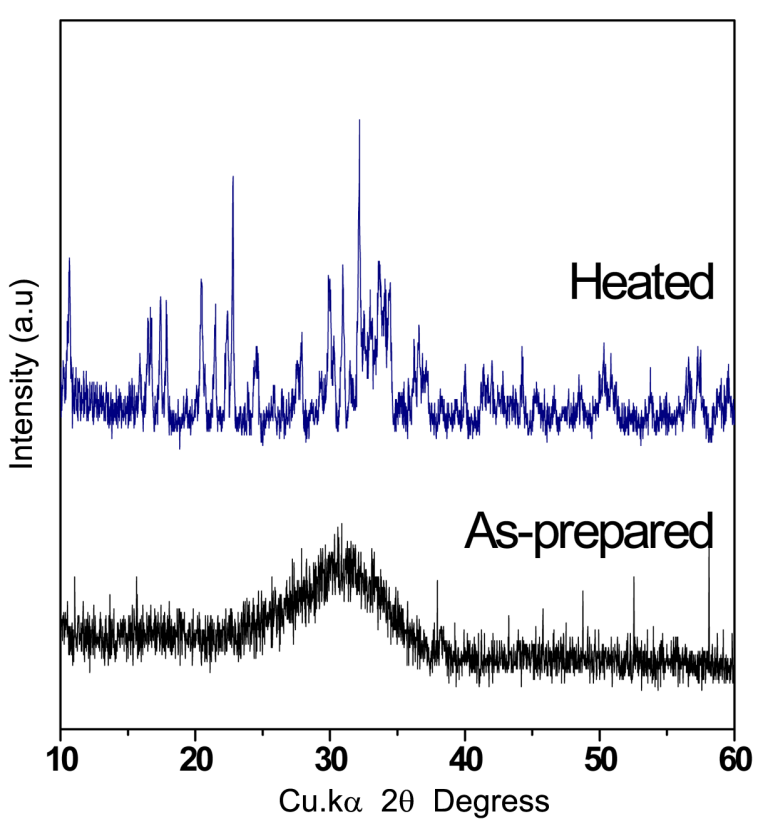

Fig. 1. X-ray diffraction patterns of as-prepared and $650^{\circ} \mathrm{C}$ annealed $\mathrm{Na}_{2} \mathrm{FeP}_{2} \mathrm{O}_{7}$ samples by polyol-assisted pyrosynthesis.
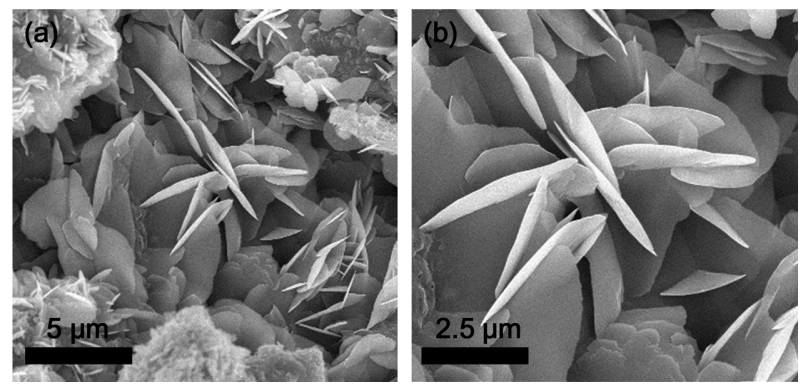

Fig. 2. FE-SEM images of annealed $\mathrm{Na}_{2} \mathrm{FeP}_{2} \mathrm{O}_{7}$ sample low resolution (a) and high resolution (b).

leading to the formation of crystalline particles from the polyol-assisted pyro-synthesis. Further, the polyol medium, which acts as a conductive carbon source and limits the particle growth. ${ }^{16,23,24)}$ During the fast combustion, the polyol can be pyrolyzed, which also results in carbonization of the polyol. ${ }^{16)}$ The carbonized structures act as physical barriers to prevent particle growth and also form a thin conductive carbon layer coated on the $\mathrm{Na}_{2} \mathrm{FeP}_{2} \mathrm{O}_{7}$ particles. This improves the electron conductivity, thus resulting in good electrochemical performance.

The electrochemical performance of the $\mathrm{Na}_{2} \mathrm{FeP}_{2} \mathrm{O}_{7}$ electrode vs. $\mathrm{Na}^{0} / \mathrm{Na}^{+}$is presented in Fig. 3. The charge/discharge curves of the $\mathrm{Na}_{2} \mathrm{FeP}_{2} \mathrm{O}_{7}$ cycled between 2.0 and 4.0 $\mathrm{V}$ at $0.08 \mathrm{C}$ are shown in Fig. 3(a). Initial discharge capacity of $80.8 \mathrm{~mA} \mathrm{~h} / \mathrm{g}$ was observed with a small plateau at $2.5 \mathrm{~V}$ and a large plateau at $3 \mathrm{~V}$, which can be ascribed to structural rearrangement or Na-ion ordering during the electrochemical reaction. ${ }^{13)}$

The cycle performance of the $\mathrm{Na}_{2} \mathrm{FeP}_{2} \mathrm{O}_{7}$ electrode is 

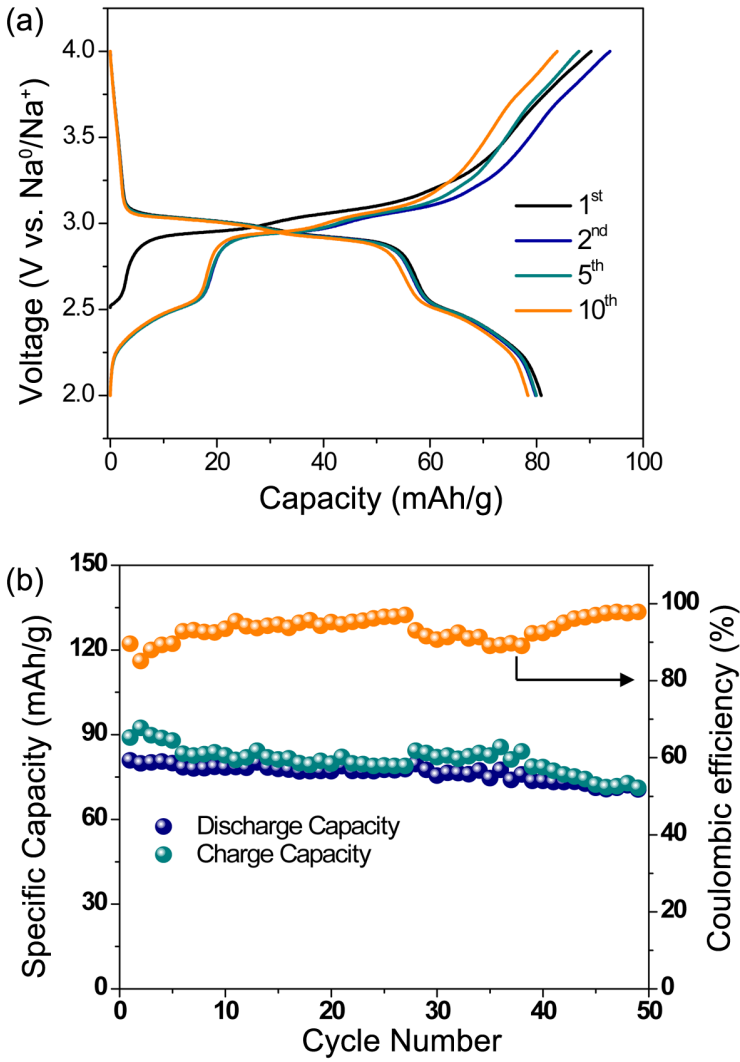

Fig. 3. Electrochemical charge-discharge curves (a) and cycle performance (b) of $\mathrm{Na}_{2} \mathrm{FeP}_{2} \mathrm{O}_{7}$ electrodes in potential range of $2.0-4.0 \mathrm{~V}$ at $0.08 \mathrm{C}$.

shown in Fig. 3(b). The discharge capacity showed stable performance with $90 \%$ of the initial capacity retained after 50 cycles at a $0.08 \mathrm{C}$ rate for the electrode $(73 \mathrm{~mA} \mathrm{~h} / \mathrm{g})$. Moreover, almost $100 \%$ Coulombic efficiencies are maintained even under prolonged cycling, as can be observed in Fig. 3(b). To further examine the rate performance, we investigated the specific capacity of the $\mathrm{Na}_{2} \mathrm{FeP}_{2} \mathrm{O}_{7}$ cathode under various current densities from 0.08 to $10.5 \mathrm{C}$ in a potential range of $2.0-4.0 \mathrm{~V}$ by cycling it three times at each rate, and the results are shown in Fig. 4(a). The $\mathrm{Na}_{2} \mathrm{FeP}_{2} \mathrm{O}_{7}$ electrode exhibited discharge capacities of 46 and $16 \mathrm{~mA} \mathrm{~h} / \mathrm{g}$ at 1.31 and $5.25 \mathrm{C}$, respectively. The capacity of the electrode recovered to $82 \mathrm{~mA} \mathrm{~h} / \mathrm{g}$ at a rate of $0.08 \mathrm{C}$, demonstrating the stability of the electrode. At a current density of $0.08 \mathrm{C}$, two plateaus can be observed in the discharge curve from Fig. 4(b). Further, at a higher current density, the plateaus become less clear, indicating larger polarization. To investigate long-term cycling, the $\mathrm{Na}_{2} \mathrm{Fe} \quad \mathrm{P}_{2} \mathrm{O}_{7}$ electrode was cycled at a rate of $0.8 \mathrm{C}$. The results in Fig. 5 showed good cycling stability performance of the electrode. The electrode registered first and $200^{\text {th }}$ discharge capacities of 56 and 48 $\mathrm{mA} \mathrm{h/g}$, respectively. Further, as evidenced form Fig. 5, the Coulombic efficiencies are maintained at around 95\% upon extended cycling. The excellent electrode properties are mainly attributed to the highly cross linked structure comprising nano-plate $\mathrm{Na}_{2} \mathrm{FeP}_{2} \mathrm{O}_{7}$ with carbon content.
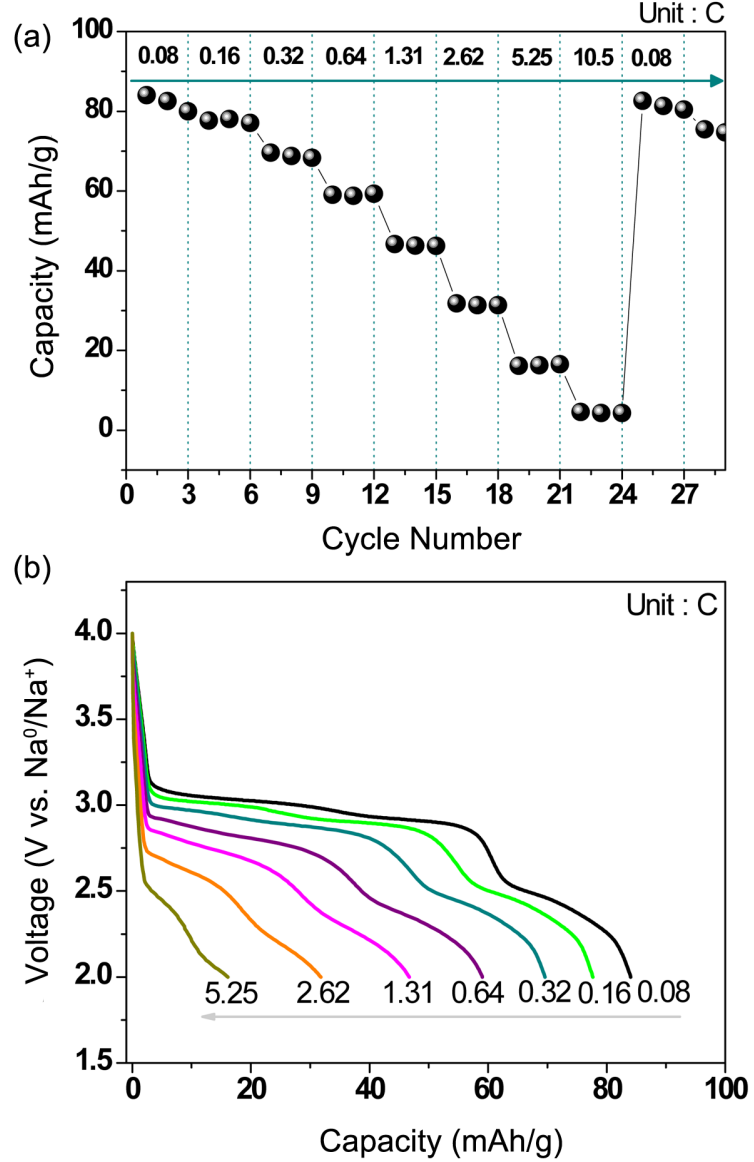

Fig. 4. Rate performance of $\mathrm{Na}_{2} \mathrm{FeP}_{2} \mathrm{O}_{7}$ electrode (a) and corresponding discharge curves (b) under 0.08-10.5 C.

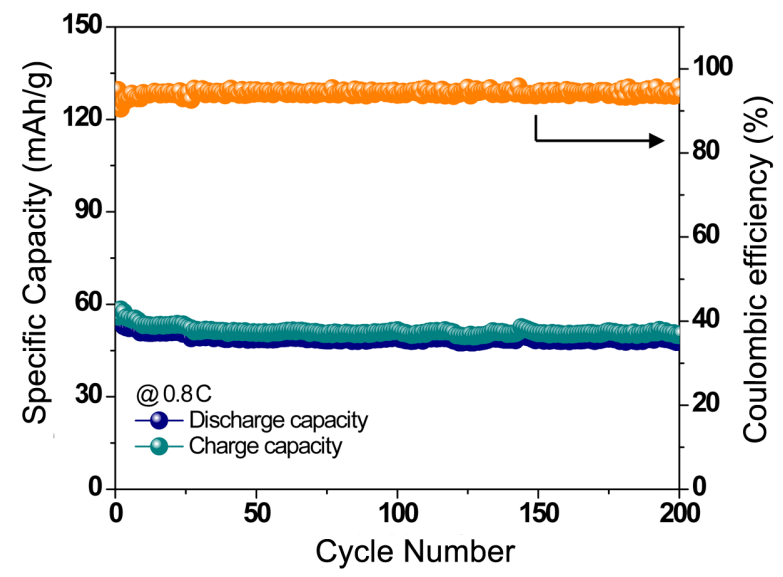

Fig. 5. Cycle performance in potential range of $2.0-4.0 \mathrm{~V}$ at $0.8 \mathrm{C}$.

\section{Conclusions}

In summary, carbon-coated $\mathrm{Na}_{2} \mathrm{FeP}_{2} \mathrm{O}_{7}$ cathode materials were successfully synthesized by a simple and low-cost pyro-synthesis method. The XRD patterns of the sample were well matched to triclinic $\mathrm{Na}_{2} \mathrm{FeP}_{2} \mathrm{O}_{7}$ without any impurity phase. The sample showed average particle size of 
about 2 - $5 \mu \mathrm{m}$ with a cross linked nano-plate shape. The prepared $\mathrm{Na}_{2} \mathrm{FeP}_{2} \mathrm{O}_{7}$ cathode demonstrated initial discharge capacities of $80 \mathrm{~mA} \mathrm{~h} / \mathrm{g}$ within a potential window of $2-4.0 \mathrm{~V}$ and showed good cyclability under long term cycling. The pyro-synthesis strategy offers opportunities to prepare carbon-coated cross linked nanoplate particles, which are not only well connected with the electrode and electrolyte and give short ion diffusion paths but also improve the electron conductivity, thus resulting in good electrochemical performance. In addition, this technique appears to be useful for synthesizing a variety of other materials suited for next generation $\mathrm{Na}$-ion batteries.

\section{Acknowledgments}

This work was supported by the National Research Foundation of Korea (NRF) grant funded by the Korea government (MSIP) (2014R1A2A1A10050821). It was also supported by Industrial Strategic technology development program, (Project No. 10050477, Development of separator with low thermal shrinkage and electrolyte with high ionic conductivity for Na-ion batteries) funded by the Ministry of Trade, industry \& Energy (MI, Korea).

\section{REFERENCES}

1. M. D. Slater, D. Kim, E. Lee, and C. S. Johnson, "SodiumIon Batteries," Adv. Funct. Mater., 23 [8] 947-58 (2013).

2. B. L. Ellis and L. F. Nazar, "Sodium and Sodium-Ion Energy Storage Batteries," Curr. Opin. Solid State Mater. Sci., 16 [4] 168-77 (2012).

3. S. W. Kim, D. H. Seo, X. Ma, G. Ceder, and K. Kang, "Electrode Materials for Rechargeable Sodium-Ion Batteries: Potential Alternatives to Current Lithium-Ion Batteries," Adv. Energy Mater., 2 710-21 (2012).

4. V. Palomares, P. Serras, I. Villaluenga, K. B. Hueso, J. Carretero-González, and T. Rojo, "Na-Ion Batteries, Recent Advances and Present Challenges to Become Low Cost Energy Storage Systems," Energy Environ. Sci., 5 [3] 5884901 (2012).

5. C. Masquelier, A. K. Padhi, K. S. Nanjundaswamy, and J. B. Goodenough, "New Cathode Materials for Rechargeable Lithium Batteries: The 3-D Framework Structures $\mathrm{Li}_{3} \mathrm{Fe}_{2}$ $\left.\left(\mathrm{XO}_{4}\right)_{3} \mathrm{X}=\mathrm{P}, \mathrm{As}\right), " J$. Solid State Chem., 135 [2] 228-34 (1998).

6. J. Jiang and J. R. Dahn, "ARC Studies of the Thermal Stability of Three Different Cathode Materials: $\mathrm{LiCoO}_{2}$; $\mathrm{Li}\left[\mathrm{Ni}_{0.1} \mathrm{Co}_{0.8} \mathrm{Mn}_{0.1}\right] \mathrm{O}_{2}$; and $\mathrm{LiFePO}_{4}$, in $\mathrm{LiPF}_{6}$ and $\mathrm{LiBoB} \mathrm{EC} /$ DEC Electrolytes," Electrochem. Commun., 6 [1] 39-43 (2004).

7. J. Barker, M. Y. Saidi, and J. L. Swoyer, "A Sodium-Ion Cell Based on the Fluorophosphate Compound $\mathrm{NaVPO}_{4} \mathrm{~F}$," Electrochem. Solid-State Lett., 6 [1] A1-4 (2003).

8. K. Zaghib, J. Trottier, P. Hovington, F. Brochu, A. Cuerfi, A. Mauger, and C. Julien, "Characterization of Na-based Phosphate as Electrode Materials for Electrochemical Cells," J. Power Sources, 196 [22] 9612-17 (2011).

9. K. T. Lee, T. N. Ramesh, F. Nan, G. Botton, and L. F.
Nazar, "Topochemical Synthesis of Sodium Metal Phosphate Olivines for Sodium-Ion Batteries," Chem. Mater., 23 [16] 3593-600 (2011).

10. F. Sauvage, E. Quarez, J. M. Tarascon, and E. Baudrin, "Crystal Structure and Electrochemical Properties vs. $\mathrm{Na}^{+}$ of the Sodium Fluorophosphate $\mathrm{Na}_{1.5} \mathrm{VOPO}_{4} \mathrm{~F}_{0.5}$," Solid State Sci., 8 [10] 1215-21 (2006).

11. Y. Kawabe, N. Yabuuci, M. Kajiyama, N. Fukuhara, T. Inamasu, R. Okuyama, I. Nakai, and S. Komaba, "Synthesis and Electrode Performance of Carbon Coated $\mathrm{Na}_{2} \mathrm{Fe}$ $\mathrm{PO}_{4} \mathrm{~F}$ for Rechargeable Na Batteries," Electrochem. Commun., 13 [11] 1225-28 (2011).

12. N. Recham, J.-N. Chotard, L. Dupont, K. Djllab, M. Armand, and J.-M. Tarascon, "Ionothermal Synthesis of Sodium-based Fluorophosphate Cathode Materials," J. Electrochem. Soc., 156 [12] A993 (2009).

13. P. Barpanda, T. Ye, S. I. Nishimura, S. C. Chung, Y. Yamada, M. Okubo, H. Zhou, and A. Yamada, "Sodium Iron Pyrophosphate: A Novel 3.0 V Iron-based Cathode for Sodium-Ion Batteries," Electrochem. Commun., 24 [1] 11619 (2012).

14. Y. H. Jung, C. H. Lim, J.-H. Kim, and D. K. Kim, " $\mathrm{Na}_{2} \mathrm{FeP}_{2} \mathrm{O}_{7}$ as a Positive Electrode Material for Rechargeable Aqueous Sodium-Ion Batteries," RSC Adv., 4 [19] 9799 (2014).

15. M. Y. Saïdi, J. Barker, H. Huang, J. L. Swoyer, and G. Adamson, "Performance Characteristics of Lithium Vanadium Phosphate as a Cathode Material for Lithium-Ion Batteries," J. Power Sources, 119-121 266-72 (2003).

16. J. Gim, V. Mathew, J. Lim, J. Song, S. Baek, J. Kang, D. Ahn, S.-J. Song, H. Yoon, and J. Kim, "Pyro-Synthesis of Functional Nanocrystals," Sci. Rep., 2 1-6 (2012).

17. H. Kim, R. A. Shakoor, C. Park, S. Y. Lim, J. S. Kim, Y. N. Jo, W. Cho, K. Miyasaka, R. Kahraman, Y. Jung, and J. W. Choi, " $\mathrm{Na}_{2} \mathrm{FeP}_{2} \mathrm{O}_{7}$ as a Promising Iron-based Pyrophosphate Cathode for Sodium Rechargeable Batteries: A Combined Experimental and Theoretical Study," Adv. Funct. Mater., 23 1147-55 (2013).

18. L. Zhang, H. Xiang, Z. Li, and H. Wang, "Porous $\mathrm{Li}_{3} \mathrm{~V}_{2}\left(\mathrm{PO}_{4}\right)_{3} / \mathrm{C}$ Cathode with Extremely High-Rate Capacity Prepared by a Sol-Gel-Combustion Method for Fast Charging and Discharging," J. Power Sources, 203 [9] 12125 (2012).

19. S. Patoux, C. Wurm, M. Morcrette, G. Rousse, and C. Masquelier, "A Comparative Structural and Electrochemical Study of Monoclinic $\mathrm{Li}_{3} \mathrm{Fe}_{2}\left(\mathrm{PO}_{4}\right)_{3}$ and $\mathrm{Li}_{3} \mathrm{~V}_{2}\left(\mathrm{PO}_{4}\right)_{3}, " J$. Power Sources, 119-121 278-84 (2003).

20. H. Liu, G. Yang, X. Zhang, P. Gao, L. Wang, J. Fang, J. Pinto, and X. Jiang, "Kinetics of Conventional Carbon Coated- $\mathrm{Li}_{3} \mathrm{~V}_{2}\left(\mathrm{PO}_{4}\right)_{3}$ and Nanocomposite $\mathrm{Li}_{3} \mathrm{~V}_{2}\left(\mathrm{PO}_{4}\right)_{3}$ / Graphene as Cathode Materials for Lithium Ion Batteries," J. Mater. Chem., 22 [22] 11039-47 (2012).

21. P. Barpanda, G. Liu, C. D. Ling, M. Tamaru, M. Avdeev, S. C. Chung, Y. Yamada, and A. Yamada, " $\mathrm{Na}_{2} \mathrm{FeP}_{2} \mathrm{O}_{7}$ : A Safe Cathode for Rechargeable Sodium-Ion Batteries," Chem. Mater., 25 [17] 3480-87 (2013).

22. Y. Wu, Z. Wen, and J. Li, "Hierarchical Carbon-Coated $\mathrm{LiFePO}_{4}$ Nanoplate Microspheres with High Electrochemical Performance for Li-Ion Batteries," Adv. Mater., 23 [9] 
1126-29 (2011).

23. D.-H. Kim and J. Kim, "Synthesis of $\mathrm{LiFePO}_{4}$ Nanoparticles in Polyol Medium and Their Electrochemical Properties," Electrochem. Solid-State Lett., 9 [9] A439 (2006).
24. L. Qiu, V. G. Pol, J. Calderon-Moreno, and A. Gedanken, "Synthesis of Tin Nanorods via a Sonochemical Method Combined with a Polyol Process," Ultrason. Sonochem., 12 [4] 243-47 (2005). 